\title{
Biannual Prize for the Most Outstanding Contribution to the Journal 2018-2019
}

It is with great pleasure that the Editorial Board announces that the 2020 Biannual Prize is awarded to Stephen Egharevba for his article 'Minority Perception of Police Legitimacy in Finland: The Patterns and Predictors', which appeared in the 2018(4) issue of the Journal.

As the author points out, the perception of the police by minorities and racial groups is an issue of very considerable topical importance in contemporary societies. Yet it is also one that has received insufficient attention, and about which insufficient is known. Therefore, while the article is primarily concerned with the situation in Finland, it stands out as making an important contribution to criminological debate in Europe (and beyond). Moreover, as the author grounds his study in the evolving theoretical literatures on procedural justice, legitimacy, confidence, and trust, the article has the capacity to add to these literatures as well as to develop the intellectual agenda of the field relating to minorities and policing.

At the core of the article is a piece of empirical work. The editors were impressed by its coherent methodology, by the clarity with which the study had been informed by the theoretical literature, and by the sophistication with which the empirical work had been written up. Added to its substantive attributes, the article stands out for its intellectual precision. The author writes with great definitional clarity and the article is well-structured. He also conveys an engaging enthusiasm for his subject, which means, quite simply, that the article is an excellent read!

For all of the above reasons, and in the context of a significant number of other strong contributions, we have no doubt that Stephen Egharevba is an extremely worthy winner of the third Biannual Prize. Like previous winners, the article represents, at the highest level, the standards of originality, significance and rigour that we would like to see reflected in the contributions that we receive.

The Editorial Board is also especially pleased that, for the first time, the prize has been awarded to an article that is built around a piece of empirical research. As we reiterated in the 2019(3) Editorial, we are as keen to receive contributions that are criminological in kind as those that are more legal in 
nature. We hope that the presence within our pages of criminological articles of this exemplary quality will encourage further, similar contributions, thereby promoting our ambition to offer a lively environment for interdisciplinary dialogue and scholarship regarding crime, criminal law and criminal justice in Europe.

Estella Baker

Editor and Professor of European Criminal Law and Justice, De Montfort University on behalf of the Editorial Board

$4^{\text {th }}$ February 2020 